\title{
Study of lead levels in soils by weathering of metallic Pb bullets used in dove hunting in Córdoba, Argentina
}

\begin{tabular}{|r|l|}
\hline Journal: & X-Ray Spectrometry \\
\hline Manuscript ID: & XRS-13-0065.R1 \\
\hline Wiley - Manuscript type: & Research Article \\
\hline Date Submitted by the Author: & n/a \\
\hline Complete List of Authors: & $\begin{array}{l}\text { Rubio, Marcelo; CEPROCOR, Unidad Estudios Físicos } \\
\text { Germanier, Alejandro; CEPROCOR, Unidad Estudios Físicos } \\
\text { Mera, María Fernanda; CEPROCOR, Unidad Estudios Físicos } \\
\text { Faudone, Sonia Nerina; CEPROCOR, Unidad Estudios Físicos } \\
\text { Sbarato, Rubén Darío; Facultad Regional San Francisco (UTN), Física } \\
\text { Campos, José Manuel; Facultad Regional San Francisco (UTN), Física } \\
\text { Zampar, Vanesa; CEPROCOR, Unidad Estudios Físicos } \\
\text { Bonzi, Edgardo; Facultad de Matemática, Astronomía y Física - Universidad } \\
\text { Nacional de Córdoba, Física } \\
\text { Pérez, Carlos; Brazilian Synchrotron Light Source, Fluorescence and } \\
\text { Absorption group }\end{array}$ \\
\hline Keywords: & \begin{tabular}{l} 
XRF, Lead, Hunting, Contamination, bullets \\
\hline
\end{tabular} \\
\hline
\end{tabular}


Study of lead levels in soils by weathering of metallic Pb bullets used in dove hunting in Córdoba, Argentina

$\underline{\text { M. Rubio }}^{1,2,3}$, A. Germanier ${ }^{1}$, M.F. Mera ${ }^{1}$, S. N. Faudone ${ }^{1}$, R.D. Sbarato ${ }^{4}$, J.M. Campos ${ }^{4}$ V. Zampar ${ }^{1}$, E. Bonzi ${ }^{2}$, C.A. Pérez ${ }^{5}$

${ }^{1}$ CEPROCOR, A. de Arenales 230, Córdoba, Argentina

${ }^{2}$ Facultad de Matemática, Astronomía y Física (FAMAF), Universidad Nacional de Córdoba, Ciudad Universitaria, Córdoba, Argentina

${ }^{3}$ CONICET, Rivadavia 1917, Buenos Aires, Argentina

${ }^{4}$ Facultad Regional San Francisco, Universidad Tecnológica Nacional, Av. Universidad 501, San Francisco, Córdoba, Argentina

${ }^{5}$ LNLS, Laboratorio Nacional de Luz Sincrotron, Campinas, Brazil.

Key words: XRF, Lead, Hunting, Contamination

\begin{abstract}
A study of level of $\mathrm{Pb}$ in soils of the centre-north of the Province of Córdoba, a worldwide recognized tourist region for dove hunting, was performed in this work. The native forest of the region has a great population of doves associated with the grains productive fields of the surrounding. Contamination of soils due to hunting activities is regulated by national and local norms. The Córdoba Environmental Secretary by resolution $\mathrm{N}^{\mathrm{o}} 1115 / 2011$ approved a new regulation that categorizes this activity as generator of Y31 (Pb) industrial waste. Lead from pellets alloy is deposited on the soil of the shooting fields. Samples were taken at depth of $50 \mathrm{~mm}$ from 315 pits referenced by GPS in accordance with local environmental authorities as well as the hunting outfitters companies. Sampling sites are distributed between parallels $31^{\circ} \mathrm{S}$ (S31) up to $30{ }^{\circ} \mathrm{S}$ (S30) and between meridians W64 up to W63. Soils samples were analysed by Xray fluorescence spectroscopy (XRF) while $\mathrm{Pb}$ bullets were analysed by scanning electron microscopy (SEM) and X-ray diffraction (XRD). The average concentration obtained for $\mathrm{Pb}$ in dry soil sieved (200 mesh) was 80 ppm. Powder XRD patterns of crust material removed from the corroded surface of weathered bullets were obtained. Three $\mathrm{Pb}$ mineral compounds were identified by XRD analysis and also studied by optical microscopy and SEM.
\end{abstract}




\section{INTRODUCTION}

Deforestation due to agriculture expansion is threatening the north of Argentina that integrates a part of Semi-arid Chaco region of South America. This is a partial effect of the increase in rainfall that has modified the environment of the subtropical region of Argentina during the last five decades ${ }^{[1]}$. The region allows grain cultivation such as soybean, corn, sorghum and wheat. This food source is surrounded by native forest, and the combination of food source and roost has raised the population of Zenaida Auriculata (Paloma in Spanish language). This is a consequence that has increased hunting activity in Argentina covered by Argentinean hunting law and resolutions.

Dove hunting cooperates to maintain native forest areas because it competes with deforestation for agricultural purposes. However, a continuous monitoring of lead levels is necessary to set limits to this activity when the values of concentrations are close to the maximum limit allowed. This systematic control should be guaranteed to ensure the sustainable use of natural resources providing equilibrium between regional economy, ecology and sport hunting activities.

Hunters use ammunitions made by a lead antimony alloy where $\sim 6 \% \mathrm{Sb}$ is minority while $\mathrm{Pb}$ over $90 \%$ is a major component. Metal is not stable during the contact period of bullets in soil. They progressively react and secondary lead minerals phases coated the pellets forming a crust that cover the alloy. During the weathering process grains of crust removed from the coating become an important source of bioavailability of $\mathrm{Pb}$ in the biosphere. For this reason it is interesting to describe the mineralogical composition and spatial distribution of $\mathrm{Pb}$ species around corroding ammunitions.

In 2011 the environmental authorities of Córdoba regulated the dove hunting activity and consequently our laboratory at Centro de Excelencia en Productos y Procesos (CEPROCOR) received the order to measure the concentration of lead in hunting soils. In this project we used conventional X-ray fluorescence analysis (XRF) to measure $\mathrm{Pb}$ in soil samples obtained from 315 sampling pits referenced by GPS, in 36 firing fields of north-east of Córdoba. We also performed the characterization of $\mathrm{Pb}$ mineral phases in bullets by X-ray diffraction analysis (XRD) and scanning electron microscopy (SEM). The location of the mineral phases of lead (litharge in the core and dominant hydrocerussite outer crust of bullets) is crucial to understand how the metallic $\mathrm{Pb}$ reacts 
in the soil solution, as a way to understand the real magnitude of contamination in order to develop efficient remediation programs for those hunting sites ${ }^{[2,3,4,5,6,7]}$.

\section{CHARACTERIZATION OF THE SITE}

\section{Geography of the site}

The region under study is located in a rectangle area limited by the parallels S30 04.771 and S31 21.897 and the meridians W64 17.315 and W63 00.00, as is shown in Fig. 1(a). It was adopted the World Geodetic System 84 (WGS 84) protocol to show the GPS coordinates in degrees, minutes and thousandths of minutes for latitude (S) as well longitude (W). Samples collection where taken from hunting lands at $150 \mathrm{~m}$ of altitude in the east up to $650 \mathrm{~m}$ in the west. No samples were taken in the region situated in the surrounding of the "Anzenuza" lake because no sport hunting activities are developed there.

The west side of the study region is crossed by the "North Hill". This sector corresponds to the Pampeanas Hills that cross the province of Córdoba from north to south. This hill is composed by granitic, metamorphic and sedimentary rocks. The eastern slope of North Hills is smooth (see Fig. 1(b)), with little valleys and small hills ending in the great plain of the east, an important grain area in the centre of Argentina. The highland valleys on the west of the rectangle are dominated by native forest and natural pastures. The low lands of the east called "loess pampa" have a plain relief with a gradient less than $0.3 \%$ to the east ${ }^{[8]}$. It is crossed by the rivers "Suquia" and "Xanaes" two of the five main rivers of Córdoba. Even these lands are strongly subdivided due to agricultural activities; it is possible to find clusters of native forest of chañar and algarroba trees. These forests are roosting areas for dove life.

\section{Soil}

East side: The geomorphology of soils from east is "Flat pampa" with plain relief, slow runoff with well drained drainage. The biota consists of grasses and crops. The water table is greater than $8 \mathrm{~m}$ presenting climatic, biologic and physics degradation due to anthropic factors as main limitation. The soil can be classified as Argiustol, tipic, from the family of fine limosa ${ }^{[8]}$. 
North side: The geomorphology of soils is "Montain sideslopes" with steep relief, slope between $5-10 \%$, very rapid runoff, moderate permeability and excessively drained. The soils is classified as Calciustol Petrocálcico ${ }^{[8]}$. The biota is composed by heterogeneous forest with autochthonous trees and shrubs. The region has extensive livestock, low infrastructure available and native vegetation.

\section{Climate}

The study area is extended over a template region. The climate of the region produces two factors for promoting the dove hunting most of the year: diversity of grain crops providing large food supply and pleasant weather conditions for tourist. Argentinean doves do not migrate and they reproduce up to four times a year, providing a year-round hunting.

The annual average (1960-present) of rainfall inside the study zone is $850 \mathrm{~mm}$ with an annual hydric excess from February to May ${ }^{[9]}$. The Normalized Difference Vegetation Index (NDVI) -green index- has a progressive increment since the last three decades.

\section{EXPERIMENTAL}

Soil sample preparation

In 2012 soils samples were collected in 36 hunting zones placed in the Nort-East of the Province of Córdoba. They are distributed in an area shown in the rectangle of Fig. 1(a). The sampling procedure consisted to collect soil material on each analyzed site at 50 $\mathrm{mm}$ depth in 10 GPS referenced points symmetrically distributed in a $100 \times 100 \mathrm{~m}$ square. Nine sampling points were equally distributed in the square perimeter and one in the centre. Samples collected in the central point were taking at 5 and $15 \mathrm{~cm}$ depth. Samples were duplicated, labeled, dated and packed in each hunting zone and were sent to CEPROCOR for analysis and the duplicate samples to local environmental authorities for custodial.

An aliquot of 80 grams of sample was dried in an oven at $60^{\circ} \mathrm{C}$ during 24 hs to remove water and volatile compounds. After cooling at room temperature it was carefully grounded using a porcelain mortar to reduce the granulometry to dust. This material was 
sieved in a plastic sieve of 200 mesh $(74 \mu \mathrm{m})$. Finally, $4 \mathrm{~g}$ of this powder were mixed with $1 \mathrm{~g}$ of cellulose and pressed at 20 tons in a matrix of $40 \mathrm{~mm}$ diameter. The pressed pellet samples obtained after different experimental tests were very stable, without surface or border failures. To assure the traceability, a numerical code was applied to each pressed pellet sample and correlated with the original raw material storage package and also with the powder recipient before blending. A database computer program saved each code with information about geomorphology setting, the analytical procedure and the post-analysis location of the XRF disk, powder and original raw material for control.

\section{XRF}

Multielemental quantitative analysis of elements from Na to $U$ was performed by XRF spectrometry in 315 soil samples from 36 hunting sites located on east and north sides of the rectangle of Fig. 1(a).

The Resolution 1115/11 of the environmental authorities of the Province of Córdoba established that $\mathrm{Pb}$ concentration must be determined in dried and sieved soil (mesh $200,74 \mu \mathrm{m})$. This procedure excludes to grind the bullets that remain retained on the sieve. The XRF quantification carried out by our laboratory at CEPROCOR reported the amount of lead in sieved soil after removing the weathered pellets.

Fluorescence intensities were measured using a $4 \mathrm{~kW}$ power Bruker SRS 3400 wavelength dispersive spectrometer. The $\mathrm{x}$-ray tube has a thin Be window $(75 \mu \mathrm{m})$ to optimize the detection limit. The spectrometer includes six Bragg analyser crystals, OVOB, OVOC, OVO55, PET, LIF 200 and LIF 220, allowing it to measure elements from $\mathrm{Na}$ up to $\mathrm{U}$. $\mathrm{Pb} \mathrm{L} \alpha_{1} \mathrm{x}$-ray fluorescence intensity was measured using a LIF 200 crystal, fine collimator of $0,15^{\circ}$, voltage $60 \mathrm{kV}$, electric current intensity of $67 \mathrm{~mA}$, mask $34 \mathrm{~mm}$ and vacuum mode. Both detectors flow counter and scintillation counter were used simultaneously ${ }^{[10]}$.

$\mathrm{pH}$ determination in soil

The properties of soil like organic matter and $\mathrm{pH}$ develop an important function in the weathering of metallic $\mathrm{Pb}$ bullets in dove shooting fields. The soluble secondary minerals obtained from transformation of $\mathrm{Pb}$ bullets are a mechanism for $\mathrm{Pb}$ 
mobilization in soils. In presence of organic matter and low $\mathrm{pH}$ the transformation of metallic $\mathrm{Pb}$ to secondary $\mathrm{Pb}$-minerals are more rapid. Lower soil $\mathrm{pH}$ is determinant to increase the solubility of $\mathrm{Pb}$ providing more mobilization of $\mathrm{Pb}$ into the soil. On the other hand, reducing organic matter and increasing soil $\mathrm{pH}$ slowed weathering of metallic $\mathrm{Pb}$ in a soil ${ }^{[11]}$. No organic matter in soil was determined in this work.

Soil $\mathrm{pH}$ was determinated following the procedure of USEPA Method 9045D (2004) Soil and Waste $\mathrm{pH}$ at a soil to deionized water ratio of 1:2 (w/v), using pHmeter with glass electrode Sartorius model PP-20. Soil $\mathrm{pH}$ was determined for samples corresponding to the central point ( $5 \mathrm{~mm}$ depth) of each analyzed site of $100 \mathrm{~m} \times 100 \mathrm{~m}$ square.

Crust samples

Ammunition retained in soil samples sieving were separated and classified. Most of them look coated by a crust of brown and gray material as a cause of weathering conditions. A powder product of this corrosion crust was obtained by mixing groups of 15 bullets during $15 \mathrm{~s}$. The method was developed by our laboratory and the optimized time was determined controlling the quantity and crystallinity of the crust power removed from the bullets. Too much time may produce altered crystals while fewer seconds may not disperse clusters of crystals.

Powder X-ray diffraction patterns were collected with a Bruker AXS D8 Advance diffractometer operated with a $\mathrm{Cu} \mathrm{K \alpha}$ x-rays source and a post-diffraction graphite monochromator, at $40 \mathrm{kV}, 40 \mathrm{~mA}$. The powder was loaded over zero background silicon sample holder. During the data collection, the sample holder was rotated in a plane parallel to its surface at a speed of $30 \mathrm{rpm}$ to reduce preferred orientation effects. The powder mounts were scanned over a Bragg angle from $2^{\circ}$ to $70^{\circ} 2 \square$, with a step size of $0.05^{\circ} 2 \square$ and count time of 9 seconds per step.

\section{RESULTS}

Soil Analysis

$\mathrm{XRF}$ quantification was carried out by a standard addition curve of $\mathrm{Pb}$ in a mixture of uncontaminated soil, in a concentration range from 0 to $1000 \mathrm{ppm}$. The lower detection 
limit for $\mathrm{Pb}$ in soil was determined in $15 \mathrm{ppm}$ assuming a limit of quantification of 40 ppm for this work. This value was empirically determined and supported by reasonable experimental data. The background level of lead in soil of $40 \mathrm{ppm}$ was calculated by extrapolating the standard addition curve to none fluorescent intensity. Other authors have determined lead concentrations lower than $50 \mathrm{ppm}$ in uncontaminated soil, but in many urban areas those exceed 200 ppm $^{[11,12,13]}$.

Figure 2 shows the $\mathrm{x}$-ray fluorescence spectrum of a sample of soil taken from a hunting activity pit belongs to region E delimited by the rectangle of Fig 1(a). The linear X-scale selected for XRF spectrum allows to superimpose scans measured with different crystals, showing the spectrum easily readable, well spread on the whole useable range for XRF (from about $30 \mathrm{keV}$ to $0.13 \mathrm{keV}$ in our equipment). That is the reason why the $\mathrm{X}$-scale is labeled $7.5-\sqrt{\mathrm{E}}$, where 7.5 has been arbitrarily chosen in order to reach the energy limit for $\mathrm{C} \mathrm{K} \alpha$ lines.

Table 1 shows the concentration of the major elements in soil corresponding to the spectrum of Figure 2.

Lead concentration results for 315 soil samples collected from 36 sport firing sites are shown in figure 3. The histogram represents the distribution of $\mathrm{Pb}$ concentrations for all dove hunting sites located on the region delimited by the rectangle studied. The concentration range goes from 40 (lowest quantification limit) to $474 \mathrm{ppm}$ as maximum value obtained. The average concentration value for $\mathrm{Pb}$ was calculated in $80 \mathrm{ppm}$.

Figure 4 shows the correlation between the values of soil $\mathrm{pH}$ and total $\mathrm{Pb}$ concentration values obtained for soil samples of the 36 firing sites measured. It can be seen that higher values of $\mathrm{Pb}$ were found in acid soils.

\section{Analysis of crust}

Powder XRD qualitative analysis of the phases was performed by the DIFFRACplus EVA® software (Bruker-AXS, Germany) based on the ICDD Powder Diffraction File database (PDF card numbers 33-1161, 24-0586, 13-0131, 05-0561 and 04-0686).

Figure 5 shows the PXRD patterns of mineral phases of crust removed from bullets of zones $\mathrm{H}$ and $\mathrm{F}$ (north) and zone $\mathrm{E}$ (east) of the region represented by the rectangle in Fig. 1(a). Encrustation of Hydrocerussite $\left(\mathrm{Pb}_{3}\left(\mathrm{CO}_{3}\right)_{2}(\mathrm{OH})_{2}\right)$, Litharge (PbO-tetragonal) 
and Hydroxypyromorphite $\left(\mathrm{Pb}_{5}\left(\mathrm{PO}_{4}\right) 3(\mathrm{OH})\right)$ were found in this work. Quartz appears as an adhering soil contamination in crust, it is not a mineral phase formed from pellets composition. A small amount of metallic lead was identified in samples of both zones.

Optical, laser and Scanning Electron Microscopy (SEM)

A Motic optical microscope (40x) was used to observe the whole spheroids bullets and a Lext 3D Laser microscope OLS 4000 Olympus to observe the crust grown in the surface of the pellets. All these apparatus belong to LAMARX at the Facultad de Matemática, Astronomía y Física (FAMAF) of the University of Córdoba. Figure 6(a) shows a microphotography of a weathered bullet collected in soils of a firing field of the zone $\mathrm{F}$ (north) of the region studied. It is possible to observe the altered surface of the $\mathrm{Pb}$ alloy of the original ammunition. White zones correspond to hydrocerusite on a grey background of litharge, quartz and $\mathrm{Pb}$. In Figure 6(b) it is shown a microphotography 1400x of a region of the bullet surface of Fig 6(a) showing hydrocerusite crust (white zones).

Figure 7(a) shows a microphotography of an isolated crust grain removed from the surface of a bullet. Figures 7(b), 7(c) and 7(d) show three SEM spectra taking from different zones on the grain were the presence of chemical elements of mineral compounds were identified. The original alloy of bullets contains a small percentage of antimony being this the reason to be present in Fig 7(b) for instance. But, Sb mineral compounds cannot be detected by XRD because these phases present limited crystallinity, being almost amorphous. It is also possible to identify the element phosphorus in the spectrum of Fig. 7(d) possible due to the presence of hydroxypyromorphite. Finally, calcium is attributed to soil contamination.

\section{CONCLUSIONS}

The first study concerning the quantification of lead in dried sieved soils from fields dedicated to dove hunting was carried out in this work. XRF spectrometry was used to quantify 315 samples of soil collected in 36 firing sites of Argentina and processed in CEPROCOR. An innovative written protocol approved by the Córdoba State environmental authorities was used for sampling and quantification. 
Results show that the average concentration value of $\mathrm{Pb}$ for sieved and dried soils is 80 ppm. Only four samples showed values of concentration of $\mathrm{Pb}$ above the guidance level of 375 ppm for farmland established by the Argentinean Law $N^{\circ} 24,051$. All these cases correspond to measured fields located far from the agricultural border.

The average lead concentration is two times the value determined for natural soil of lands without human activity. Lead quantification performed in this work do not included the bullets found in the raw material used to process each sample because these pellets were removed by sieving the soil. No statistical calculation was made to determine the average number of pellets found in the material of samples, nor the total amount of pellets deposited each year in the study area. But, it could be hypothesized that pellets will continue their weathering process releasing $\mathrm{Pb}$ to soil in the future. There is an amount of $\mathrm{Pb}$ sources in each hunting site which has not yet completely 'weathered'. As these pellets continue reacting with the components of soil, the concentration of 'potentially mobile' $\mathrm{Pb}$ phases will increase in soil.

This fact requires to local authorities to continue monitoring periodically the concentration of $\mathrm{Pb}$ in soils of hunting sites to guarantee the sustainability of natural resources. When levels of lead concentration reach higher values than those permitted by the applicable environmental standards phytoremediation is inevitable for use of this land for pastoral or farming

This study also determined the species of encrusted mineral phases in the pellet surface due to reaction of metal in soil. XRD results showed that the transformation products in the crust material are predominantly Hydrocerussite associated with minor amounts of litharge and not well crystallized Hydropyromorphite. Special attention was paid to the identified phase Hydroxypyromorphite ( $\mathrm{Pb} 5(\mathrm{PO} 4) 3(\mathrm{OH}))$ because the presence of $\mathrm{P}$. We are now studying if this compound is due to waste of fertilizer released in soils of grain lands in the borders of forest or just due to presence of natural apatite in soil.

Our laboratory is developing a project in progress for micro synchrotron radiation XRF and micro XANES mapping in crust to improve the identification, distribution and quantification of mineral phases of $\mathrm{Pb}$ as well $\mathrm{Sb}$ in weathered pellets as a continuity of these results.

\section{References}


[1] R. H. Grau, I. N. Gasparri, T. Mitchell Aide, Environmental Conservation 2005; 32 (2), 140-148

[2] D. Vantelon, A. Lanzirotti, A. C. Scheinost, R. Kretzschmar, Environ. Sci. Technol. 2005, 39, 4808-4815.

[3] D. W. Hardison Jr., L. Q. Ma, T. Luongo, W. G. Harris, Science of the Total Environment, 2004, 328, 175-183.

[4] Z. Lin, B. Comet, U Qvarfort, R Herbert, Environmental Pollution, 1995, 89, 3, 303309.

[5] X. Cao, L. Q. Ma, M. Chen, D. Hardison, W. Harris, Science of the Total Environment, 2003, 307, 179-189.

[6] D. Dermatas, M. Dadachov, P. Dutko, N. Menounou, P. Arienti, G. Shen, Global Nest: the Int. J., 2004, Vol 6, No 2, 167-175.

[7] S. Selonen, M. Liiri, R. Strömmer, H. Setälä, Environmental Toxicology and Chemistry, 2012, Vol.31, No.12, 2771-2779.

[8] J. L. Panigatti, Argentina: 200 años, 200 suelos. Ediciones INTA, 2010. ISBN No 978-987-1623-85-3.

[9] B. Jarsún, J. Gorgas, E. Zamora, H. Bosnero, E. Lovera, A. Ravelo, J. Tassile, Recursos Naturales de la provincia de Córdoba. Los Suelos. Nivel de Reconocimiento 1:500.000. Edición Agencia Córdoba Ambiente S.E - INTA EEA Manfredi, 2003, Córdoba.

[10] D. Pérez, M. Rubio, A. Bonalumi, J. Sfragulla, A. López, A. Guereschi, C. Vázquez, M. Gonzalvez, M. Luchesi, R.G. Badini, S.L. Cuffini, G. Sphan, M. Inga, A. Germanier and R.E. Servant, X-Ray Spectrom.2005; 34, 59-63.

[11] L.Q. Ma, D.W. Hardison Jr, W. G. Harris, X. Cao and Q. Zhou. Water Air Soil Pollut, 2007, 178, 297-307.

[12] American Academy of Pediatrics, Committee on Environmental Health, Pediatrics 1993, 92, 1, $176-183$

[13] Agency for Toxic Substances and Disease Registry. 2009. Toxicological profile for lead. Atlanta: US Department of Health and Human Services, Public Health Service. 


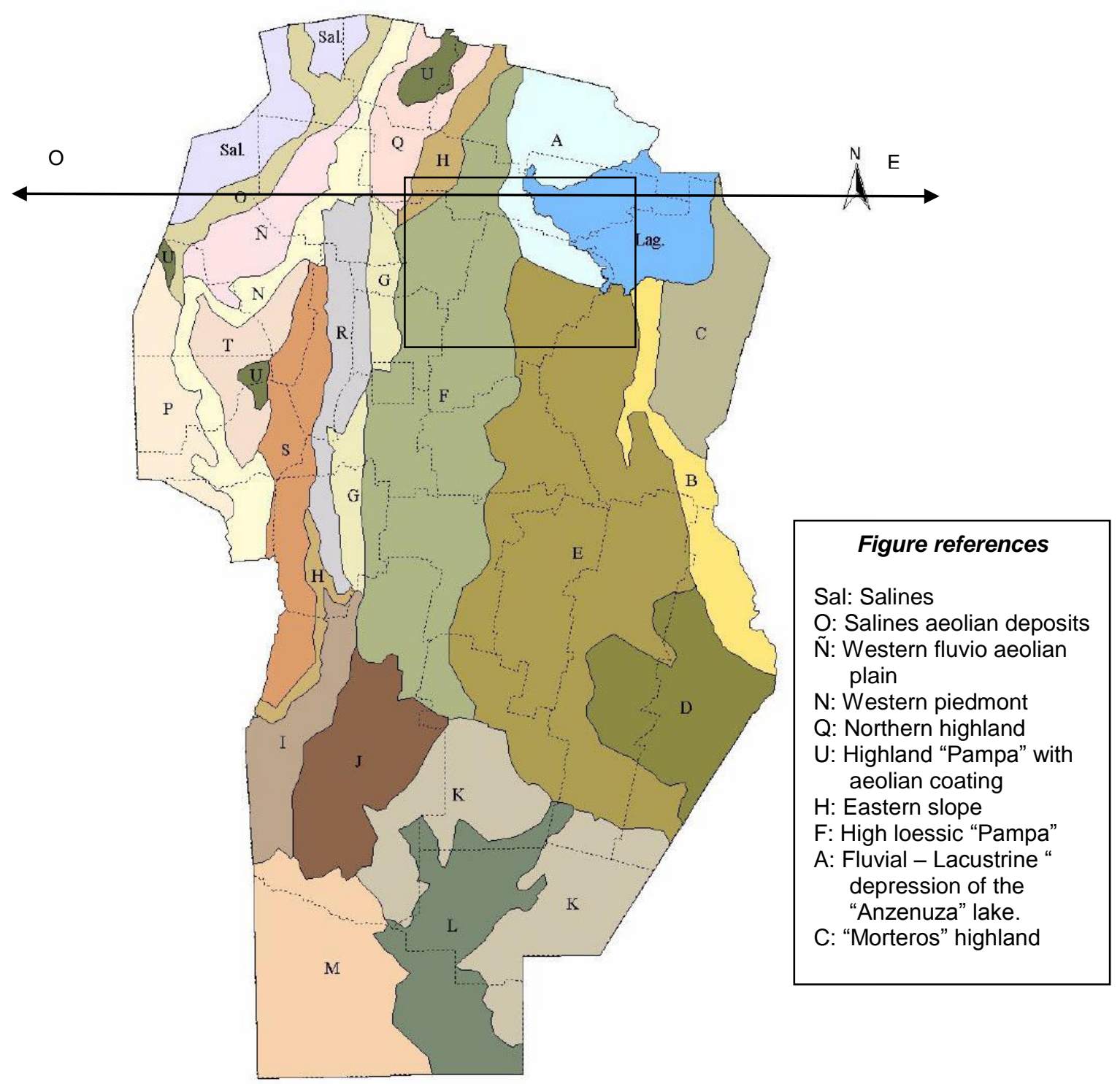

a)

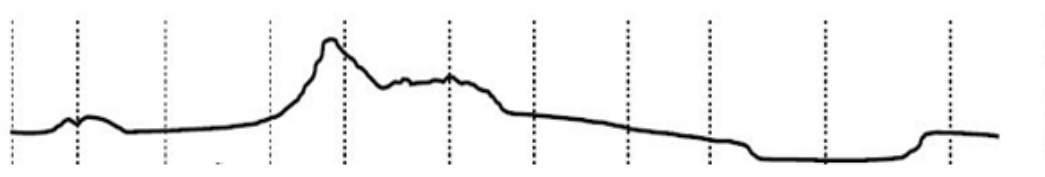

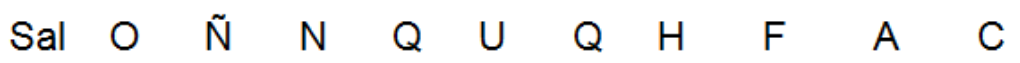

b) 
FIGURE 2

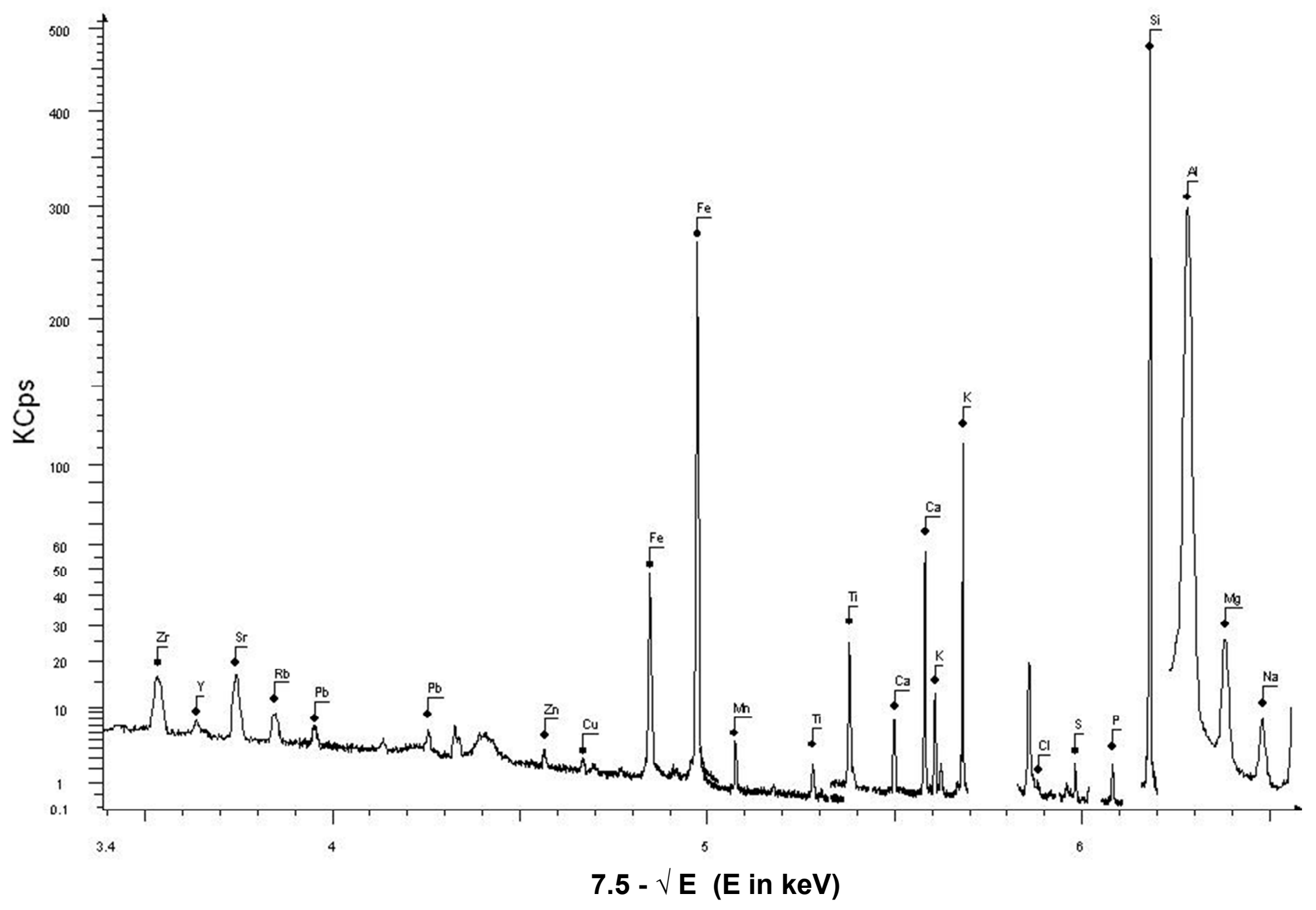

John Wiley \& Sons 
Figure 3

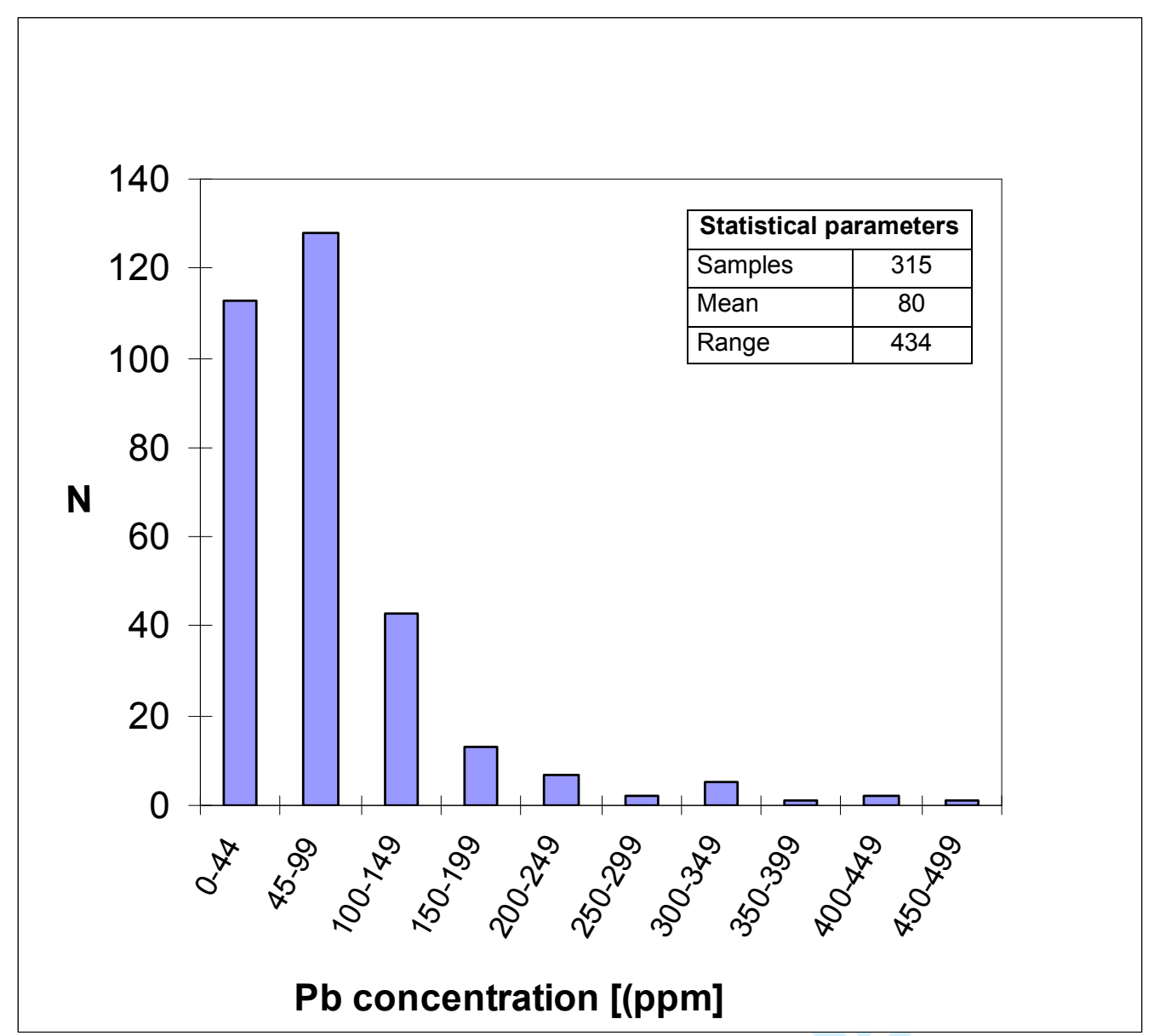

John Wiley \& Sons 
Figure 4

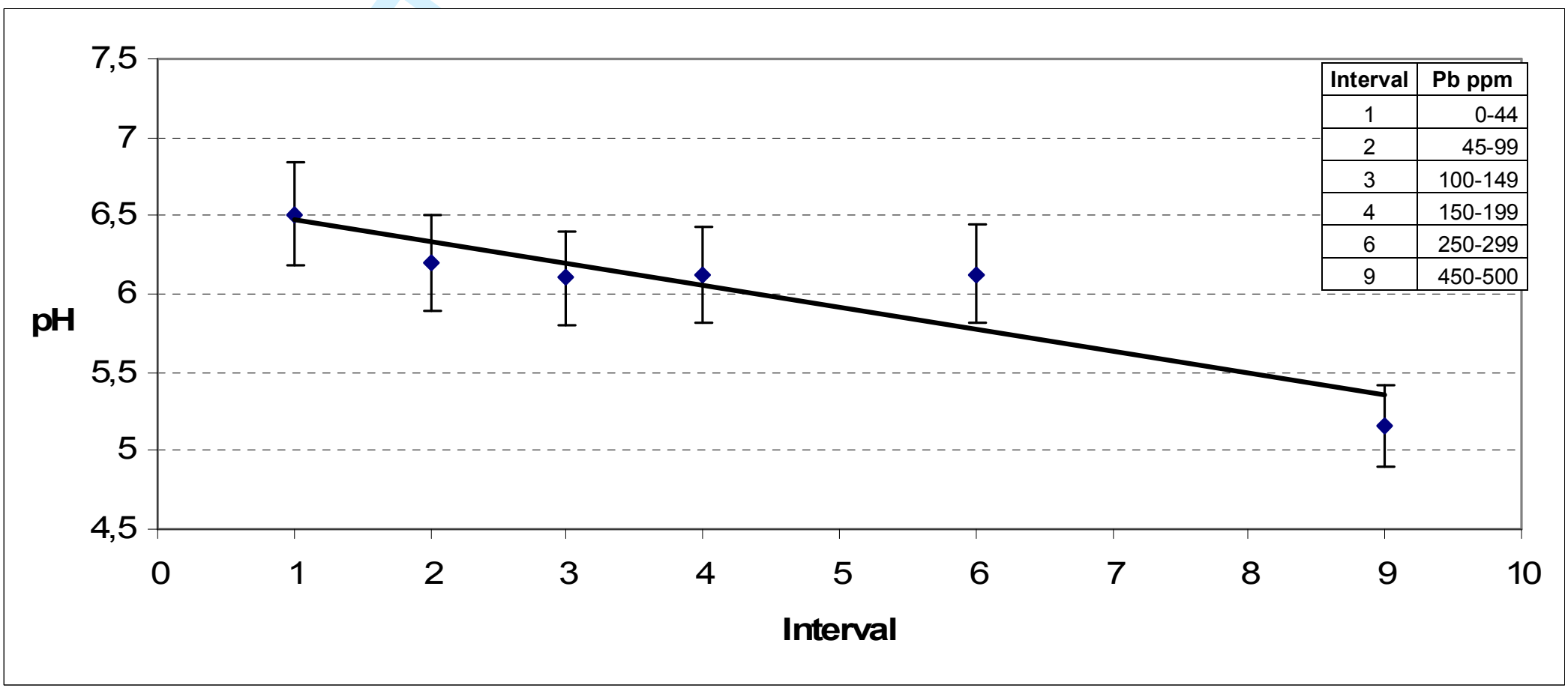


Figure 8

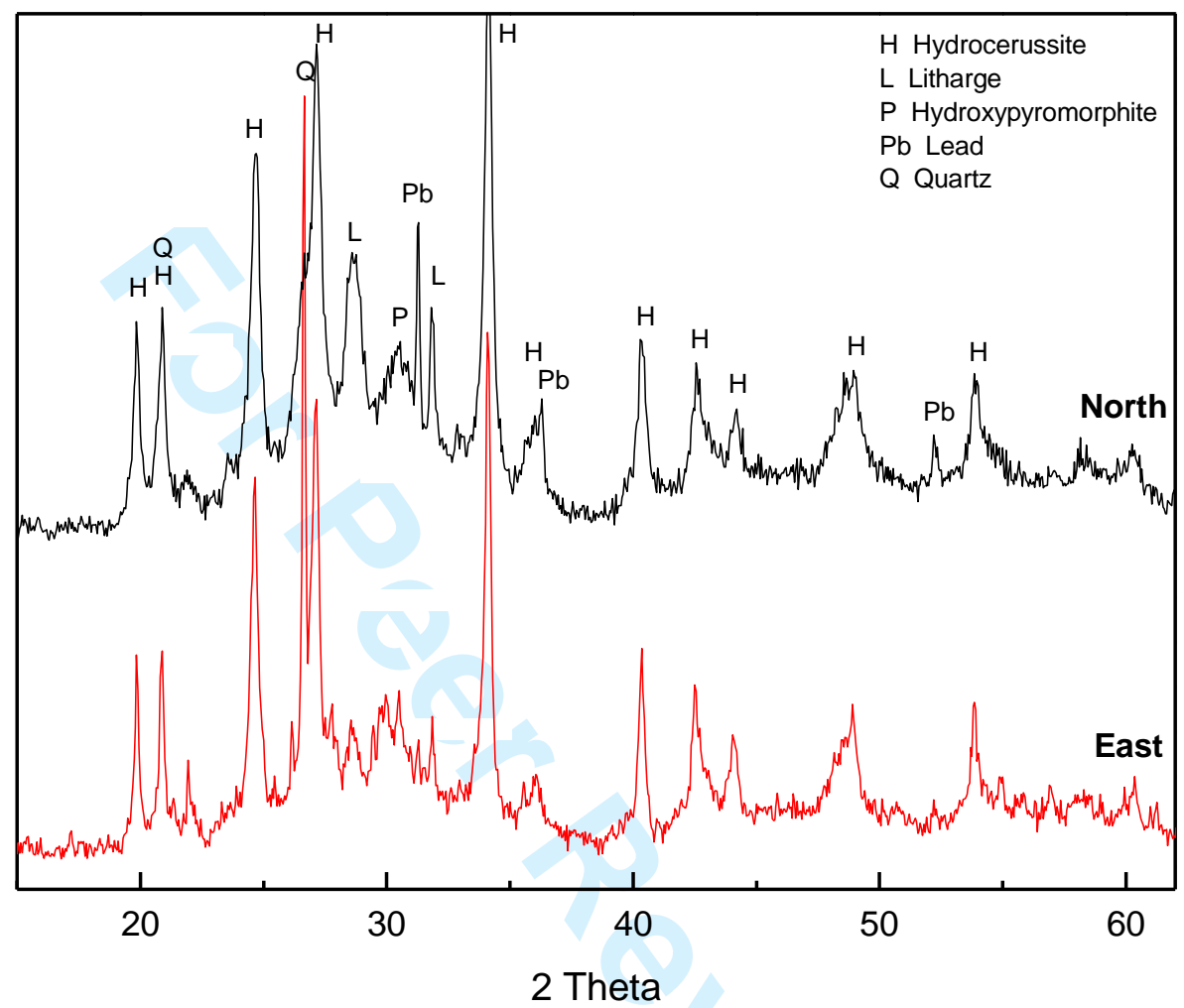


Figure 6: a) A photograph (Motic 40x) of a weathered bullet. b) Microphotography 1400x taken by a Lext 3D Laser microscope OLS 4000 Olympus of crust.

$87 \times 79 \mathrm{~mm}(96 \times 96$ DPI) 


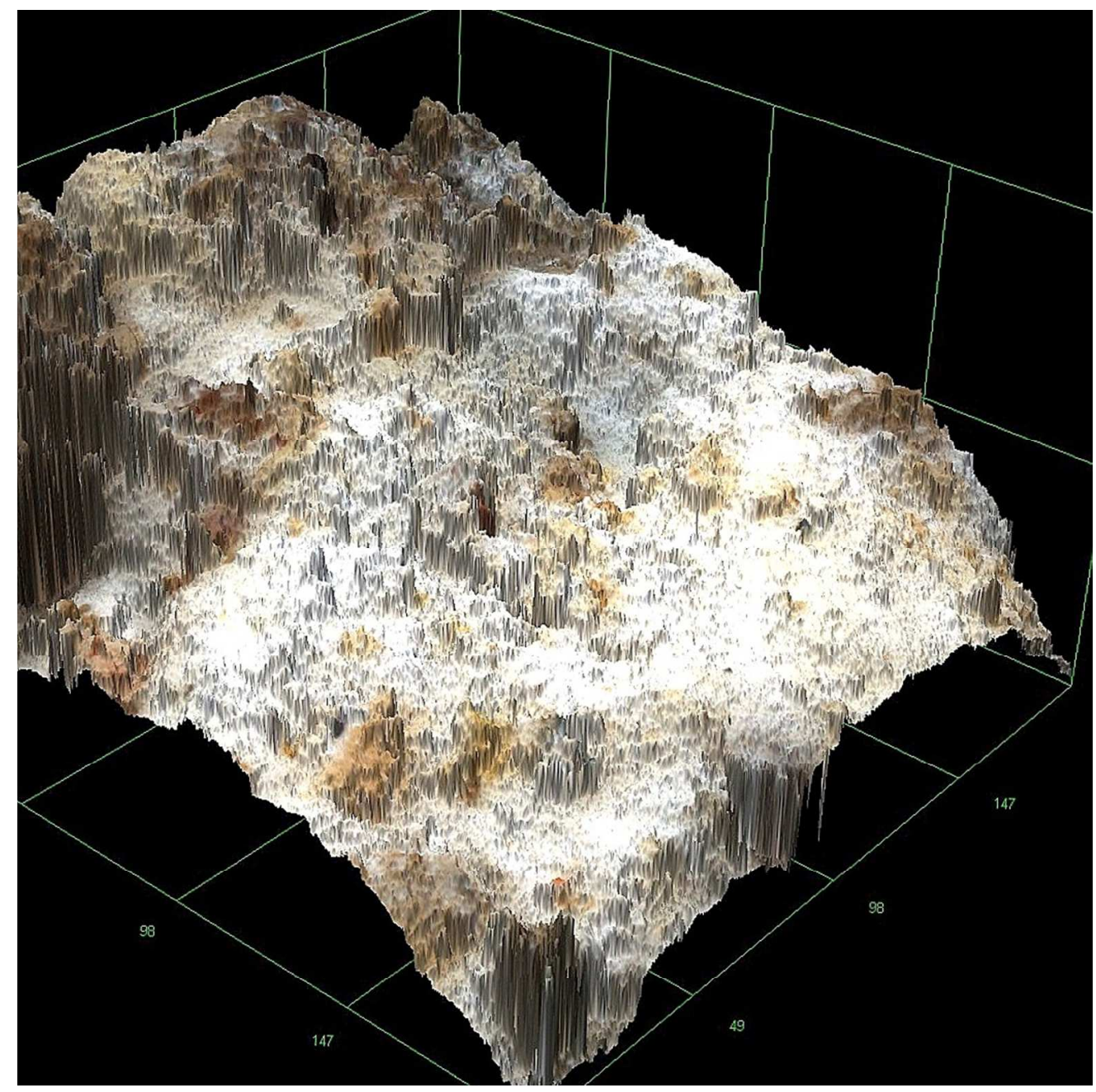

Figure 6: a) A photograph (Motic 40x) of a weathered bullet. b) Microphotography 1400x taken by a Lext 3D Laser microscope OLS 4000 Olympus of crust. $367 \times 367 \mathrm{~mm}(72 \times 72 \mathrm{DPI})$ 
Figure 7a

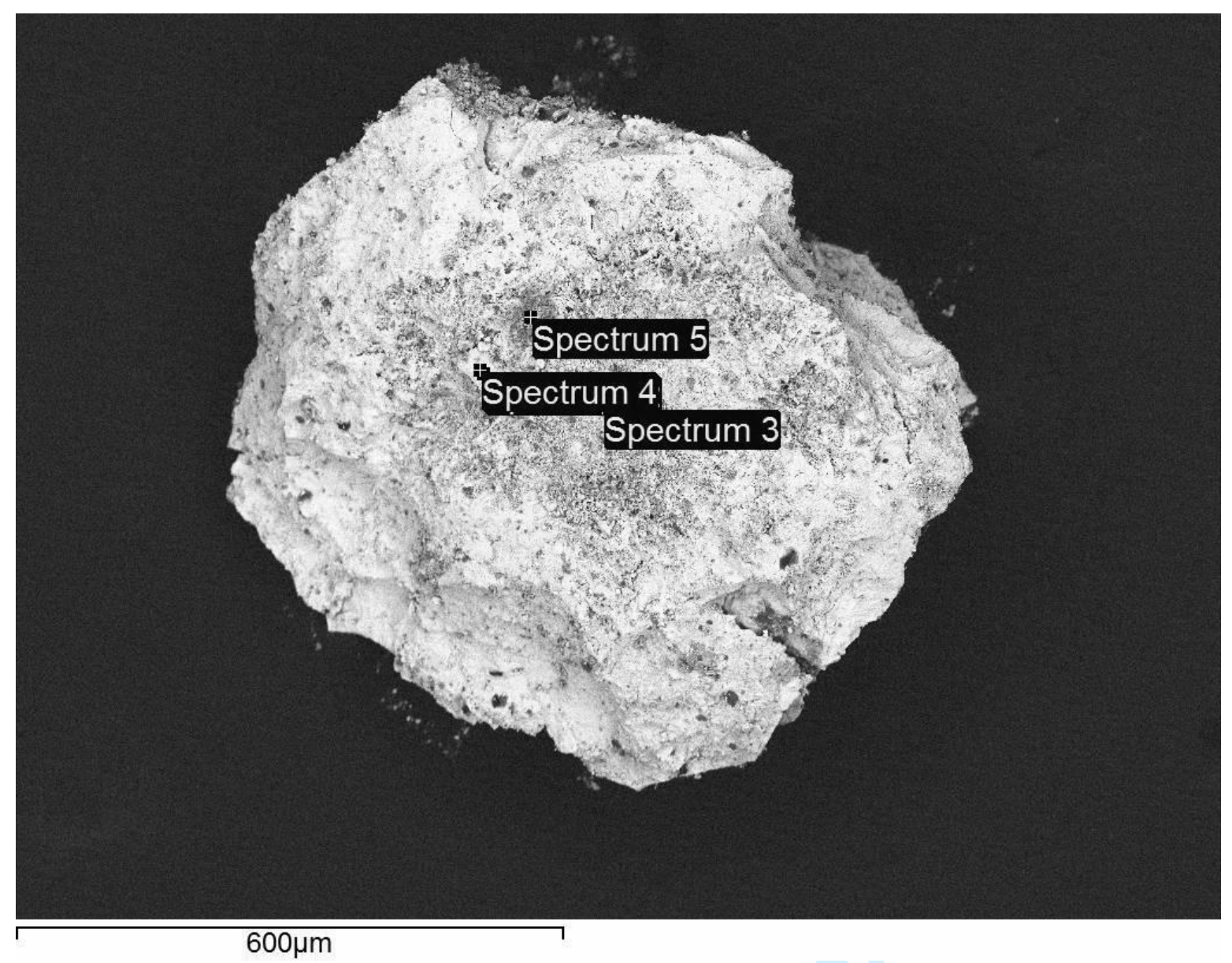

42

43

44

45

46

47

48

49

50

51

52

53

54

55

56

57

58

59

60

John Wiley \& Sons 
Figure $7 b$

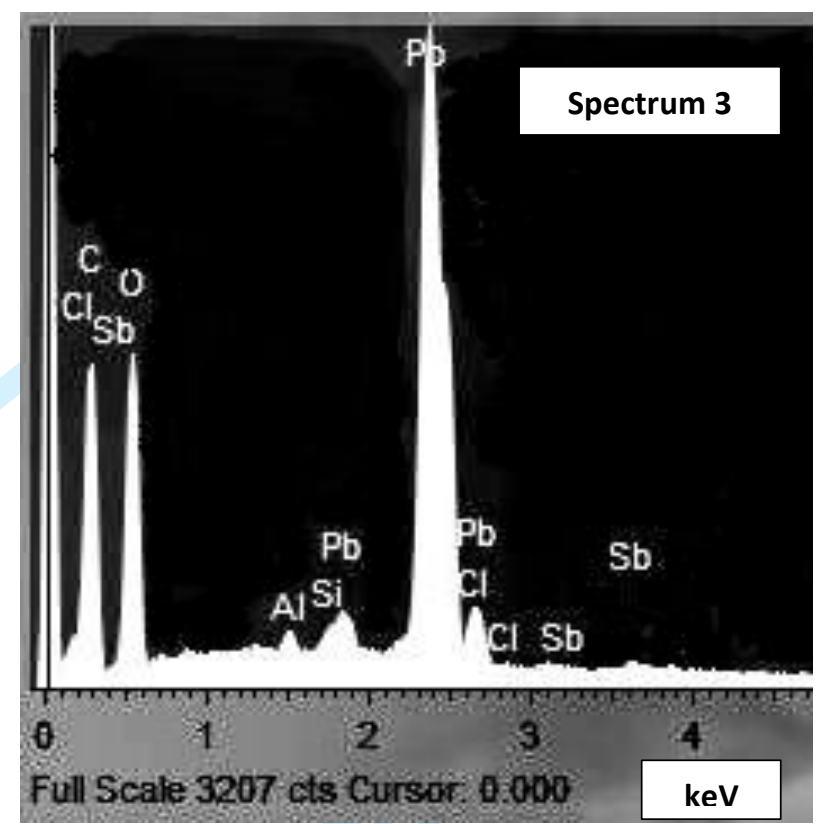

29

31

32

33

34

35

36

37

38

39

40

41

42

43

44

45

46

47

48

49

50

51

52

53

54

55

56

57

58

59

60

John Wiley \& Sons

2 (n)

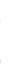




\section{Figure 7c}

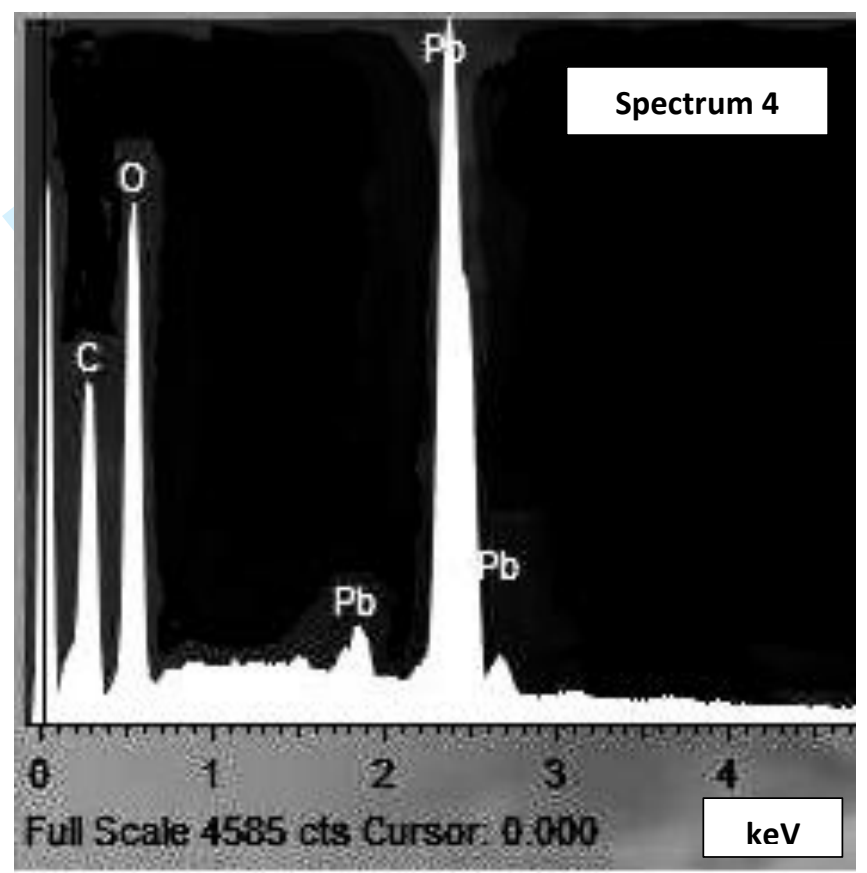

John Wiley \& Sons 
Figure 7d

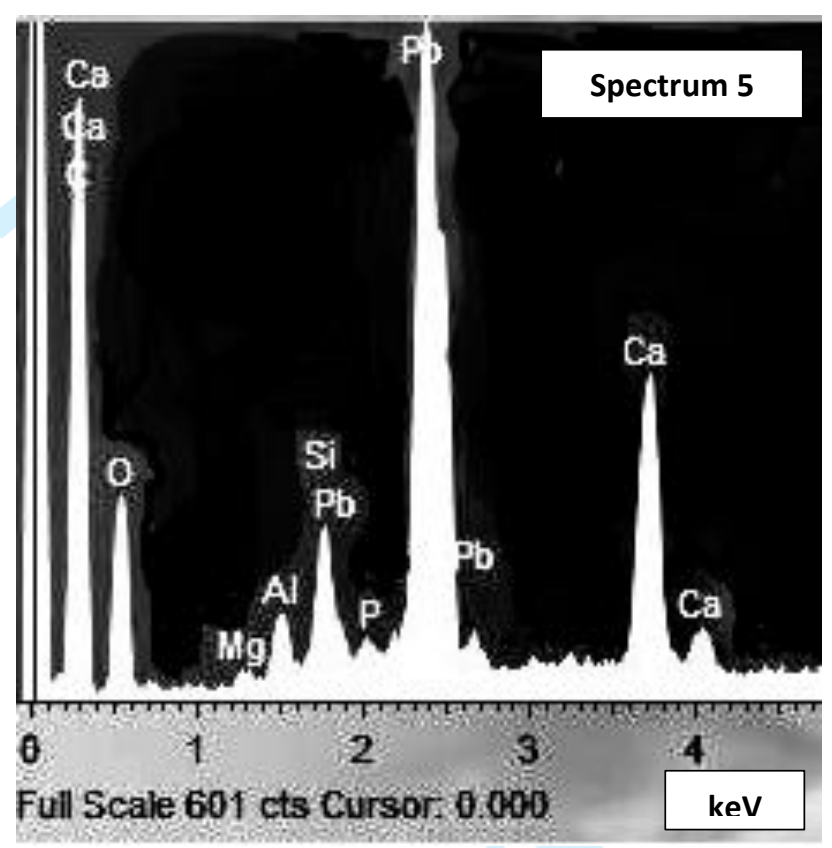

1

3

4

5

6
7

8

9

10

11

12

13

14

15

16

17

18

19

20

21

22

23

24

25

26

27

28

29

30

31

32

33

34

35

36

37

38

39

40

41

42

43

44

45

46

47

48

49

50

51

52

53

54

55

56

57

58

59

60

John Wiley \& Sons

Fuil Scale 601 cts Cursor 0.000 
Table 1

\begin{tabular}{|c|c|c|}
\hline $\begin{array}{c}\text { Compound } \\
\text { Formula }\end{array}$ & Concentration \% & $\begin{array}{c}\text { X-ray } \\
\text { Characteristic } \\
\text { line Measured }\end{array}$ \\
\hline $\mathrm{Na}_{2} \mathrm{O}$ & 1.39 & $\mathrm{Na} \mathrm{K} \alpha_{1}$ \\
\hline $\mathrm{MgO}$ & 1.18 & $M g K \alpha_{1}$ \\
\hline $\mathrm{Al}_{2} \mathrm{O}_{3}$ & 16.3 & $\mathrm{Al} \mathrm{K} \alpha_{1}$ \\
\hline $\mathrm{SiO}_{2}$ & 66.2 & Si K $\alpha_{1}$ \\
\hline $\mathrm{P}_{2} \mathrm{O}_{5}$ & 0.43 & $\mathrm{P} \mathrm{K} \alpha_{1}$ \\
\hline $\mathrm{SO}_{3}$ & 0.18 & $\mathrm{~S} \mathrm{~K} \alpha_{1}$ \\
\hline $\mathrm{Cl}$ & 0.036 & $\mathrm{Cl} \mathrm{K} \alpha_{1}$ \\
\hline $\mathrm{K}_{2} \mathrm{O}$ & 1.86 & $\mathrm{~K} \mathrm{~K} \alpha_{1}$ \\
\hline $\mathrm{CaO}$ & 2.27 & $\mathrm{Ca} \mathrm{K} \alpha_{1}$ \\
\hline $\mathrm{TiO}_{2}$ & 0.92 & $\mathrm{Ti} \mathrm{K} \alpha_{1}$ \\
\hline $\mathrm{MnO}$ & 0.108 & $\mathrm{Mn} \mathrm{K} \alpha_{1}$ \\
\hline $\mathrm{Fe}_{2} \mathrm{O}_{3}$ & 6.46 & $\mathrm{Fe} \mathrm{K} \alpha_{1}$ \\
\hline $\mathrm{CuO}$ & 0.012 & $\mathrm{Cu} \mathrm{K} \alpha_{1}$ \\
\hline $\mathrm{ZnO}$ & 0.017 & $\mathrm{Zn} \mathrm{K} \alpha_{1}$ \\
\hline $\mathrm{Rb}_{2} \mathrm{O}$ & 0.021 & $\mathrm{Rb} \mathrm{K} \alpha_{1}$ \\
\hline $\mathrm{SrO}$ & 0.055 & $\operatorname{Sr} K \alpha_{1}$ \\
\hline $\mathrm{Y}_{2} \mathrm{O}_{3}$ & 0.005 & $\mathrm{Y} K \alpha_{1}$ \\
\hline $\mathrm{ZrO}_{2}$ & 0.036 & $\mathrm{Zr} \mathrm{K} \alpha_{1}$ \\
\hline $\mathrm{PbO}$ & 0.023 & $\mathrm{~Pb} \mathrm{~L} \beta_{1}$ \\
\hline
\end{tabular}




\section{FIGURES CAPTION}

Figure 1: a) Geomorphologic map of the Province of Córdoba and the study region of this work (black line rectangle). b) The line O-E represents the latitude S30 20.000 where the geomorphologic profile shows the terrain relief characteristics.

Figure 2: X-ray fluorescence spectrum of a sample of soil collected from a hunting activity pit of the zone $\mathrm{E}$ of the study site bounded by the rectangle in Fig. 1(a).

Figure 3: Histogram of lead concentration determined by XRF analysis for all soil samples measured.

Figure 4: $\mathrm{pH}$ of soil samples correlated to soil total $\mathrm{Pb}$ concentration.

Figure 5: XRD patterns for mineral phases of crust obtained from a pool of bullets of north and east samples.

Figure 6: a) A photograph (Motic 40x) of a weathered bullet. b) Microphotography 1400x taken by a Lext 3D Laser microscope OLS 4000 Olympus of crust.

Figure 7: a) Microphotography of a grain crust remove from a bullet surface. b) SEM spectrum of point 3. c) SEM spectrum of point 4. d) SEM spectrum of point 5 showing the presence of $P$.

\section{TABLES CAPTION}

Table 1: XRF spectrometry of soil showing the composition of a sample collected from a hunting activity pit in the east of the study site bounded by the rectangle of figure 1. 